$5^{\text {th }}$ International Conference on Biotechnology Applications in Agriculture (ICBAA), Benha University, 8 April 2021, Egypt (Conference Online)

\title{
Characterization of Some Rhizobia Isolates From Various Legumes on Morphological, Biochemical and Molecular Criteria
}

\author{
Abd EL-ghany. M. Enas a , Ragaa. A. Eissa ${ }^{a}$, Abdelmegid I. Fahmia, ${ }^{a,}$, Hesham H. Nagaty ${ }^{a}$, Abdelfatah M. El- \\ Zanaty $^{\mathrm{a}}$ \\ ${ }^{a}$ Genetics department, Faculty of Agriculture, Menoufia University, Egypt.
}

\begin{abstract}
This research was conducted to characterize 24 rhizobial isolates from five legumes on morphological, biochemical, molecular aspects and determine the phylogenetic relationships among them. Rhizobial isolates were obtained from five Egyptian legumes; faba bean, lentil, pea, clover, and soybean. Morphological characterization classified isolates into fast and slow growers. Biochemical characterization using API 20E and API 20NE systems showed large diversity which may reflect their adaptation in different environments. Moreover, molecular detection for $16 \mathrm{~S}$ rDNA gene characterized 19 of them to species level. Isolates from pea, faba bean, clover and lentil came to be Rhizobium leguminosarum and isolates from soybean were Bradyrhizobium japonicum. These data reflected a narrow diversity of rhizobia in Egypt. Phylogenetic analysis of the 19 isolates confirmed that the Bradyrhizobium japonicum isolates were divergent from all other isolates. Also, the phylogram revealed that each group of isolates originated from root nodule of a certain legume formed a separate sub-cluster. Besides a narrow range of interspecies variations was found which is consistent with the idea of biovars presence among species.
\end{abstract}

Keywords: Rhizobia, Morphological, API 20E and API 20NE, 16S rDNA, Phylogenetic. 